\title{
Green synthesis of a novel bio-plasiticizer from castor oil
}

\author{
Mahua Ghosh* and Sohini Mukherjee
}

\begin{abstract}
A green process for the preparation of a biodegradable plasticizer was developed in this study. An ester was synthesized from castor oil fatty acid (COFA) and furfuryl alcohol (FA), using immobilized Candida antarctica Lipase B (NS 435) as bio catalyst. Reaction parameters were optimized and the ester (FA-COFA) obtained was characterized from their acid value, density, viscosity and flash point. Formation of ester was confirmed by structure analysis using TLC, GC and ${ }^{1}$ H-NMR spectroscopy. The biodegradability of the ester was also confirmed by microbiological study. The application of the ester as plasticizer into the ethyl cellulose films were analyzed by SEM and measuring tensile strength and elongation property. The ester showed good plasticizing ability at certain concentration.

Keywords - Furfuryl alcohol; Castor oil fatty acid; Candida antarctica lipase; Biodegradability; Plasticizer; Ethyl Cellulose.
\end{abstract}

\section{Introduction}

The utilization of renewable resources in every domestic and industrial application is receiving increasing attention in both industrial and scholastic purposes, due to concerns for ecological sustainability. The most widely used renewable raw materials include vegetable oils, polysaccharides (mainly cellulose and starch), wood and proteins. A variety of chemicals have been prepared from these biomass-derived materials. Vegetable oils represent promising route to renewable chemicals and polymers due to their availability, biodegradability and low toxicity. During the last decade, a variety of vegetable oil-based oleo-chemicals have been developed and utilised replacing petrochemicals. Fatty acid esters are most popular amongst them and find extensive use in various industries such as textiles, cosmetics, pharmaceuticals, lubricants, plasticizers, metal cutting fluids etc.

Castor oil fatty acid (COFA) contains ricinoleic acid as a major fatty acid. Ricinoleic acid has been considered as a source of many oleo chemicals after appropriate modifications due to the pendant hydroxyl group present in each ricinoleate chain especially as lubricants and plasticizers. Castor oil based plasticizers offer good performance over phthalates or other plasticizers. It is odorless and completely biodegradable [1].

In the present study we esterified COFA with furfuryl alcohol (FA). FA is a bio- molecule which polymerizes readily under acidic conditions and forms a thermo-stable polymer which is widely applied in the foundry industry to produce biodegradable and biorenewable plasticizer. The concept was to synthesize a plasticizer which maintains its cold temperature properties and imparts mechanical strength, comparable to the petroleum-based conventional plasticizers and would replace phthalate based plasticizers. Presence of aromatic ring in FA, free hydroxyl group in COFA and the ester linkage between COFA and FA may effectively impart the property of plasticizing to the new ester molecule. Implementation of lipase in the oleochemical industry has become lucrative because the conventional chemical process

Mahua Ghosh

Department of Chemical Technology, University of Calcutta India.

Sohini Mukherjee

Department of Chemical Technology, University of Calcutta India. requires high energy cost and additional purification processes [2]. The biochemical pathway for this esterification reaction was selected to protect the polymerization of FA and dehydration of COFA during the high temperature involved in the chemical pathway [3]. A good number of literatures support the successful production of fatty acid ester with various alcohols and fatty acids by lipase catalyzed esterification reaction [4-6]. But there is no report on enzymatic production of furfuryl ester except one published from our laboratory on the preparation of furfuryl oleate using Candida antarctica Lipase B as biocatalyst [5].

The present study includes process parameter optimization of the biocatalytic method of preparation of ester of FA and COFA with variation in molar ratio, reaction temperature and lipase concentration. Lipase B from Candida antarctica (NS 435) was used which is the best known immobilized enzyme for the ester preparation with non-specific nature. The ester produced was characterized for fatty acid composition, viscosity, density etc. and finally its biodegradability study was also done. The study also includes the application of the ester as plasticizer into the ethyl cellulose film.

\section{Materials and methods}

\section{A. Materials}

Pure COFA was obtained from Aloka Oil Industry, Kolkata and analyzed at laboratory for fatty acid composition by gas chromatography (GC). FA was purchased from Merck India Ltd., Mumbai, India. NS 435, Candida antarctica lipase B, immobilized using macroporous acrylic resin with a water content of $2 \%(w / w)$, a product of Novozyme India Pvt. Ltd. was obtained from Brenntag Ingredients (India) Private Limited, Mumbai, India. Ethyl cellulose was purchased from Hi-media Laboratories Pvt.Ltd.

All analytical grade chemicals were used and obtained from SRL, Mumbai, India.

\section{B. Microorganism and media component}

Ochrobactrum pseudintermedium, used in this study was previously isolated from soil of iron ore handling mine area of Durgapur, West Bengal, which was contaminated with machine lubricating oil and was identified by 16s rRNA (gene accession number KJ094035). This strain was reported to degrade lubricating oils. The medium used for the growth of the bacteria was Bushnell Haas mineral salt medium (BH medium) (Hi media, India) which was recommended for studying hydrocarbon deterioration. This medium contained gram per litre $(\mathrm{g} / \mathrm{l})$ of distilled water $\mathrm{MgSO}_{4}$ $0.2, \mathrm{CaCl}_{2}-0.02, \mathrm{KH}_{2} \mathrm{PO}_{4}-1, \mathrm{~K}_{2} \mathrm{HPO}_{4}-1, \mathrm{NH}_{4} \mathrm{NO}_{3}-1$ and $\mathrm{FeCl}_{3}-$ 0.05 .

\section{Esterification of FA and COFA}

For the esterification reactions conducted with FA (MW 98.10 $\mathrm{g} / \mathrm{mol}$ ) and COFA (MW $298.4 \mathrm{~g} / \mathrm{mol}$ in a flat bottom flask withmagnetic stirring at $200 \mathrm{rpm}$ in presence of lipase enzyme in a complete solvent free environment and under vacuum $(28 \mathrm{~mm}$ of $\mathrm{Hg}$ ). The reaction was optimized with a single reaction mixture that were studied one at a time and eventually followed in the subsequent reactions. To study the impact of the substrate molar ratio on the ester yield, the molar ratio of substrates was altered as 
1:1, 3:1 and 5:1 of FA: COFA. The temperature and immobilized lipase concentration were kept constant at $60^{\circ} \mathrm{C}$ and $10 \%(\mathrm{w} / \mathrm{w}$, on the total substrate weight) respectively at different time intervals $(0$ to $6 \mathrm{~h})$. The reverse molar ratios i.e. excess amount of COFA were not tried as the removal of excess fatty acid will be difficult from the ester of FA and COFA. Similarly optimization of temperature was done by varying the reaction temperature from 45 to $65^{\circ} \mathrm{C}$ and lipase concentration by varying the amount of lipase from 4 to $12 \%$ $(\mathrm{w} / \mathrm{w})$.

\section{Determination of Acid Value}

Acid value of the initial and intermittent reaction mixtures was determined by following standard method of AOCS [7] after separating the enzyme from the reaction mixture.

\section{E. Characterization of Ester Produced}

Physical parameters such as flash point, pour point, viscosity and density were determined by using ASTM methods [ASTM D56-05, ASTM D 97-96a, ASTM D 445-04C2, ASTM D891-2]. Production of COFA esters was monitored by thin layer chromatography (TLC) by withdrawing samples from time to time and spotting the lipid mixtures on a Silica Gel G plate $(0.2 \mathrm{~mm}$ thick). Here hexane-diethyl ether $(70: 30)$ was used as the developing solvent and different bands were visualized on iodine absorption and identified by measuring $\mathrm{Rf}$ value [8].Gas chromatographic(GC)analysis(Agilent $6890 \mathrm{~N}$ ) was done by hydrolyzing the FA-COFA ester in alkali and methylation of liberated fatty acids with BF3 in methanol [9]. ${ }^{1} \mathrm{H}$ nuclear magnetic resonance spectroscopy $\left({ }^{1} \mathrm{H}\right.$ NMR $)$ of the FA-COFA ester were performed under ambient temperature on a $300 \mathrm{MHz}$ Brucker spectrometer using $\mathrm{CDCl}_{3}$ as the corresponding solvent [10].

\section{F. Biodegradation Study}

A gravimetric study of the ester produced was done for each sample to observe the biodegradability of the product. Biodegradation of the FA-COFA ester was a five day study. Ochrobactrum pseudintermedium were grown in culture tubes, in sterile BH medium [11]. Ester was the sole carbon source of the $\mathrm{BH}$ medium and the ester were added to the medium at different weight percentages i.e. $1 \%, 2 \%, 3 \%, 4 \%$ and $5 \%(w / v)$ basis. The media containing different concentrations of ester were incubated for five days at $37^{\circ} \mathrm{C}$ for the growth of the microorganism. Absorbance of each media, containing different concentrations of ester was measured at $600 \mathrm{~nm}$ using Shimadzu (1700) UV-VIS Spectrophotometer to observe the growth of the microorganism. For each set of ester containing medium a control set was prepared without addition of bacterial inocula and the methods were repeated thrice for statistical analysis.

After the completion of the five days study, ester was extracted from the media with chloroform, dried and weighed to observe degradation of the ester by comparing the data with the initial weight of the ester added to the medium.

\section{G. Application of Ester as plasticizer}

Ethyl cellulose film samples were prepared by solvent cast method by adding ester as plasticizer [13].Scanning Electron Microscopy (SEM) was performed to observe the film texture of ethyl cellulose film. Tensile and elongation property of the film was measured by using a universal instrument of mechanical properties. All the elongation study was done in triplicates for statistical analysis.

\section{H. Statistical Analysis}

All the analysis was done in triplicates $(n=3)$. All the data are represented as means with their standard errors (Mean \pm SEM). Statistical comparisons among groups were performed using one way ANOVA. Level of significance $\mathrm{P}<0.05$ was considered by Tukey test (using Origin Pro 8 software).

\section{Results \& Discussion}

\section{A. Optimization of Reaction Parameters}

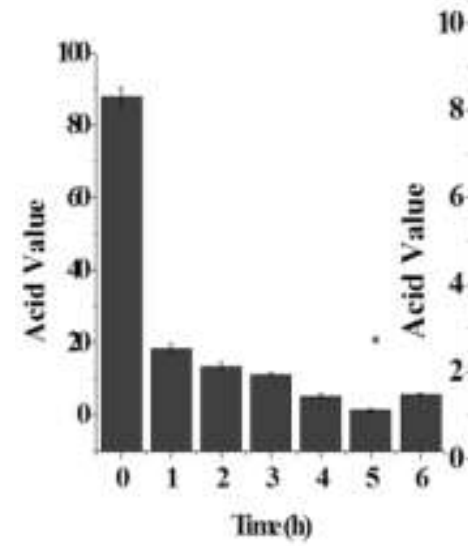

(a)

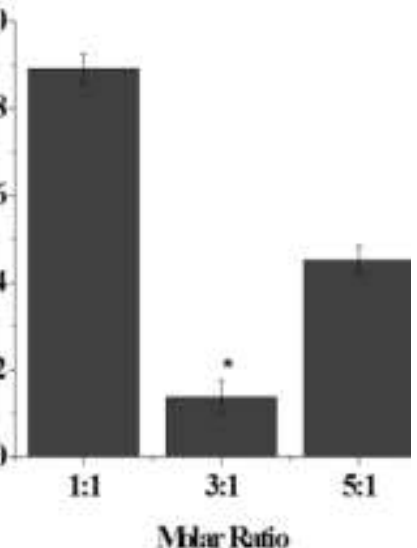

(b)

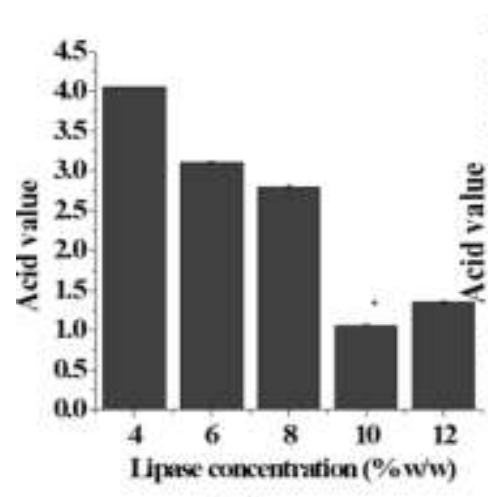

(c)

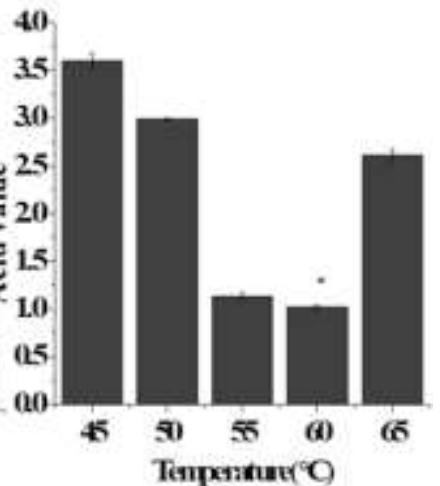

(d)
Fig. 1 Changes in acid value (a) at different time intervals $(0 \mathrm{~h}$ to 6 h) at a constant molar ratio (3:1) of FA and COFA using 10\% enzyme and at $60^{\circ} \mathrm{C}$; (b) at different molar ratios $(1: 1,3: 1$ and 5:1) of FA and COFA using 10\% enzyme, at a constant time of $5 \mathrm{~h}$ and at a constant temperature of $60^{\circ} \mathrm{C}$; (c) using different lipase concentrations ( $4 \%$ to $12 \% \mathrm{w} / \mathrm{w}$ ) at a constant temperature of $60^{\circ} \mathrm{C}$, at a constant molar ratio of 3:1 of FA and COFA; (d) at different reaction temperature $\left(45^{\circ} \mathrm{C}\right.$ to $\left.65^{\circ} \mathrm{C}\right)$ using $10 \%$ enzyme, at a constant molar ratio of $3: 1$ of FA and COFA and at a constant reaction time of $5 \mathrm{~h}$.

The progress of esterification reaction could easily be monitored by change in acid value of the reaction mixture. With the formation of ester, the acid value should decrease due to the loss of free fatty acid from the reaction mixture. Figs.1 (a) shows the change in acid value of the reaction mixture with time, keeping the other parameters constant. From Fig.1 (a), it is observed that there was a decrease in acid value with time and the highest decrease in acid value was obtained at $5 \mathrm{~h}$ of the reaction. But an increase in the acid value was observed in the $6^{\text {th }} \mathrm{h}$. Hence, from the Fig. 1 (a) it is seen that a significant $(\mathrm{P}<0.05)$ decrease in acid value was observed at the 3:1 molar ratio of FA and COFA at 5h of the reaction time. From the Fig.1(b), the decrease in acid value at molar ratio of $1: 1,3: 1$ and $5: 1$ of FA and COFA is given. With the increase in the molar ratio of FA and COFA from 1:1 to 3:1, the 
acid value was found to decrease; but a increase was noticed in 5:1 molar ratio (Fig. 1b). The decrease in the ester yield for the 5:1molar ratio of FA and COFA was quite obvious due to the deactivation of lipase due to presence of higher amount of FA. In case of 3:1 molar ratio of FA and COFA, Fig.1 (b) shows that significant $(\mathrm{P}<0.05)$ highest yield of ester in comparison to the rest of the molar ratios (e.g.1:1 and 5:1). Fig 1 (c) and (d) similarly depict the change in acid value of the reaction mixture with lipase concentration and temperature respectively. It is observed from Fig. 1 (c) that the highest decrease in acid vale was obtained at $10 \%$ (w/w on total substrate weight) lipase concentration and for $60^{\circ} \mathrm{C}$ temperature (Fig 1 (d)). Therefore, reaction time of $5 \mathrm{~h}$, the molar ratio of 3:1 of FA and COFA, $10 \%(\mathrm{w} / \mathrm{w})$ lipase concentration and $60^{\circ}$ temperature could be considered as optimum parameters for this esterification reaction.

\section{B. Characterization of Ester COFA-FA}

COFA used for the present study contained $88.80 \%$ ricinoleic acid. The fatty acid profiles of the pure COFA and the ester of FA and COFA produced at different reaction parameters were shown in the Table I. From the Table I, the fatty acid profile of FA-COFA esters produced in optimum molar ratios (3:1) of FA and COFA were determined at different time intervals ( 0 to $5 \mathrm{~h})$. Comparative study revealed that the best yield of the reaction was obtained at $5 \mathrm{~h}$ of reaction time where the highest amount of ricinoleic acid was esterified at 3:1 of molar ratio of FA and COFA, temperature of $60^{\circ} \mathrm{C}$ and with $10 \%$ (w/w) of lipase concentration.

${ }^{1} \mathrm{H}$ NMR spectra of COFA, FA and ester of FA and COFA with peak assignments confirmed the presence of carboxylic (1.653$1.674(\delta) \mathrm{ppm})$ and hydroxyl group $(1.626(\delta) \mathrm{ppm})$ in COFA, hydroxyl group $(1.760(\delta) \mathrm{ppm})$ in FA and free hydroxyl group $(1.547(\delta) \mathrm{ppm})$ in the ester.

TABLE I. FATTY ACID COMPOSITION OF CASTOR OIL FATTY ACID (COFA) AND THE ESTERS OBTAINED AT $60^{\circ} \mathrm{C}$, USING 3:1 MOLAR RATIO OF FA AND COFA, AT DIFFERENT REACTION TIMES AND AT $10 \%$ (W/W) LIPASE CONCENTRATION

\begin{tabular}{|c|c|c|c|c|c|c|}
\hline $\begin{array}{c}\text { Molar } \\
\text { Ratio of } \\
\text { FA:COFA }\end{array}$ & $\begin{array}{c}\text { Time of } \\
\text { Reaction } \\
\text { (h) }\end{array}$ & \multicolumn{6}{|c|}{ Fatty Acid Composition (\%w/w) } \\
& & $\mathbf{1 6 : 0}$ & $\mathbf{1 8 : 0}$ & $\mathbf{1 8 : 1}$ & $\mathbf{1 8 : 2}$ & $\begin{array}{c}\text { Ricinoleic } \\
\text { acid }\end{array}$ \\
\hline Pure COFA & - & 1.99 & 1.14 & 1.99 & 4.74 & $88.80 \pm 0.16$ \\
& & \pm 0.01 & \pm 0.01 & \pm 0.01 & \pm 0.07 & \\
\hline \multirow{4}{*}{$3: 1$} & 1 & 1 & 35.75 & 1.71 & 18.76 & $10.52 \pm 0.16$ \\
\cline { 2 - 7 } & 2 & 17.73 & 1.58 & 8.71 & 6.56 & $66.16 \pm 0.56$ \\
\cline { 2 - 7 } & 3 & 11.87 & 2.16 & 7.79 & 2.49 & $75.8 \pm 0.10$ \\
& & \pm 0.01 & \pm 0.01 & \pm 0.03 & \pm 0.03 & \\
\cline { 2 - 7 } & 4 & 6.57 & 1.72 & 3.86 & 1.69 & $85.91 \pm 0.34$ \\
& & \pm 0.04 & \pm 0.01 & \pm 0.03 & \pm 0.01 & \\
\cline { 2 - 7 } & 5 & 5.14 & 1.12 & 3.25 & 1.98 & $88.68 \pm 0.03^{\mathrm{a}}$ \\
\cline { 2 - 7 } & & \pm 0.03 & \pm 0.01 & \pm 0.10 & 0.01 & \\
\hline
\end{tabular}

Values are represented as Mean \pm SEM. $n=3$

${ }^{\text {a }}$ Significant at $<0.05$ in all the groups at $5 \mathrm{~h}$ reaction time at the molar ratio of 3:1 vs COFA

\section{Physical Properties of Ester}

The physical characterization of the COFA and ester of COFA were listed in the Table II. The physical properties of the COFA and ester of the FA and COFA obtained were comparable with the results obtained by other researchers. The flash point of ester of FA and COFA was $242{ }^{\circ} \mathrm{C}$. The pour point value was less than $-23^{\circ} \mathrm{C}$. The viscosity of COFA is $246.8 \mathrm{cP}$, whereas for ester of FA and
COFA, it was 17.9 at $40{ }^{\circ} \mathrm{C}$. The density of the COFA and ester of FA and COFA was almost similar.

TABLE II. PHYSICAL PROPERTIES OF COFA AND ITS ESTER

\begin{tabular}{|c|c|c|}
\hline \multirow[t]{2}{*}{ Properties } & \multicolumn{2}{|c|}{ Values } \\
\hline & COFA & Ester \\
\hline Flash Point $\left({ }^{\circ} \mathrm{C}\right)$ & $260 \pm 0.47$ & $242 \pm 0.82$ \\
\hline Pour Point $\left({ }^{\circ} \mathrm{C}\right)$ & $-21 \pm 0.81$ & $-23 \pm 0.471$ \\
\hline $\begin{array}{c}\text { Viscosity( } \mathrm{cP} \text { at } 40 \\
{ }^{\circ} \mathrm{C} \text { ) }\end{array}$ & $246.8 \pm 0.86$ & $17.9 \pm 0.68$ \\
\hline Density $\left(\mathrm{g} / \mathrm{cm}^{3}\right)$ & $0.961 \pm 0.007$ & $0.970 \pm 0.008$ \\
\hline
\end{tabular}

\section{Biodegradabilty Study}

Many bacteria have been reported to degrade different type of lubricant oils and much work has also been carried out on the degradation of lubricant, castor oil and soybean oil [12]. Studies on degradation of newly synthesized FA-COFA ester were carried out to check the biodegradability of the product.

It has been reported [1] that castor oil is biodegradable in nature and any product synthesized from this oil would be biodegradable. It would be more advantageous if the normal soil flora degrades it. Ochrobactrum pseudintermedium showed very efficient degradation of lubricating oil and hence was selected for the degradation study of the FA-COFA ester.

FA-COFA ester ranging from $0.1 \mathrm{~g}$ to $0.5 \mathrm{~g}$ (e.g. $0.1 \mathrm{~g}$ of ester added to the $10 \mathrm{ml}$ of $\mathrm{BH}$ medium) was provided as the sole source of carbon for the growth of the microorganism.

An increased growth of microorganism was observed in the spectrophotometric study where the absorbance was measured at $600 \mathrm{~nm}$. Loss of weight of the ester was also observed due to the biodegradation of the ester (Fig.2). Spectrophotometric study, as shown in the Fig.2, revealed significantly $(\mathrm{P}<0.05)$ higher growth of microorganism at $3 \%(\mathrm{w} / \mathrm{v})$ concentration of the ester at the $5^{\text {th }}$ day of the study, whereas, the rest of the ester concentration i.e, $1 \%, 2 \%, 4 \%$ and $5 \%(\mathrm{w} / \mathrm{v})$ in the growth medium showed relatively lower growth of organism in the culture media. But in each concentration of the ester, ranging from $1 \%$ to $5 \%(\mathrm{w} / \mathrm{v})$,as shown in the Fig.3, all the experimental set showed the significant $(\mathrm{P}<0.05)$ growth of microorganism against its control set. It was a noticeable part of the study that higher the concentration of the ester (e.g.4\% and 5\% w/v), the growth of the microorganism becomes static. Thus, the experiments proved the biodegradable nature of the ester. From the study it might also be inferred that higher concentrations of the product were not suitable for the growth of the organisms. After 5th day, the loss of weight of the ester of biodegradation was determined from the gravimetric study (Fig.3). Fig. 3 showed significant amount $(\mathrm{P}<0.05)$ of weight loss at the $3 \%(\mathrm{w} / \mathrm{v})$ concentration of the ester in comparison to its control set $(3 \% \mathrm{w} / \mathrm{v})$.Moreover, greater loss of weight was found at $3 \%$ $(\mathrm{w} / \mathrm{v})$ concentration in comparison to all the concentrations $(1 \%, 2 \%, 4 \%$ and $5 \% \mathrm{w} / \mathrm{v})$ of the ester. In case of $1 \%, 2 \%$ and $3 \%$ $(w / v)$ concentrations of ester, as shown in the Fig.3, there was a noticeable amount of weight loss of ester whereas, in case of $4 \%$ and 5\%, not much of loss of weight was found. Least amount of weight loss of the ester was found in the rest of the concentrations of the reaction product. Hence the optimized concentration of the reaction product for the biodegradation study was at $3 \%(\mathrm{w} / \mathrm{v})$ concentration

Since the studies were carried out in the mineral salt medium $(\mathrm{BH}$ medium) providing FA-COFA ester as the sole carbon source. 
Increase in growth of bacteria in the media as well as decreasing weight of the reaction product proved the bio-degradability of the FA-COFA ester against Ochrobactrum pseudintermedium. The degradation of the product proved that the prepared ester was completely biodegradable which is extremely desirable in terms of environmental safety. In fact, greater degradation could be achieved with lesser incubation time, depending on the nature of the product prepared.

\section{E. Application of Ester as plasticizer}

Fig.4 showed the SEM image of the ethyl cellulose film surface. SEM (Fig.4) image of the EC film containing ester displayed a smooth surface which was similar to the surface of pure EC film. Therefore, the ester was miscible with EC and even distribution was observed in the SEM image (Fig.4). Hence, it could be said that the ester as plasticizer was compatible with ethyl cellulose film.

TABLE III. MECHANICAL PERFORMANCE OF ETHYL CELLULOSE (EC) FILM

\begin{tabular}{|l|l|l|}
\hline Sample & Tensile Strength & $\begin{array}{l}\text { Elongation at } \\
\text { break }\end{array}$ \\
\hline EC & $33.21 \pm 0.73$ & $16.03 \pm 0.36$ \\
\hline EC+ESTER & $7.90 \pm 0.21$ & $20.11 \pm 0.28$ \\
\hline
\end{tabular}

Values are represented as Mean \pm SEM. $n=3$

Table III depicted the mechanical property of the ethyl cellulose film such as tensile strength and elongation at break. The tensile strength (Table 3) decreased from 33.21 MPa (Pure EC film) to 7.90 MPa (EC+ESTER). Therefore, the EC film containing ester showed better the tensile property than the films without plasticizer.Table 3 also showed the elongation property of the pure ethyl cellulose film and the ethyl cellulose film containing ester of FA and COFA. The elongation property of the ethyl cellulose film containing ester showed good performance when compared with the performance of the pure ethyl cellulose film without plasticizer. Hence the ester of FA and COFA not only contains good tensile

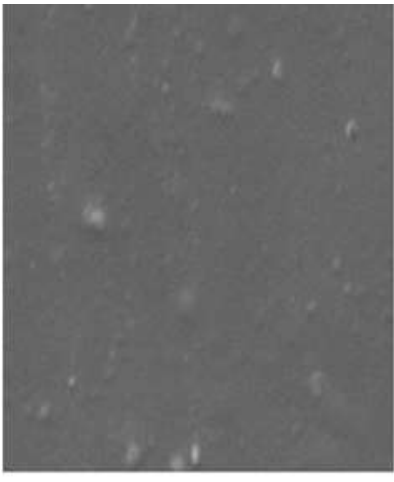

EC

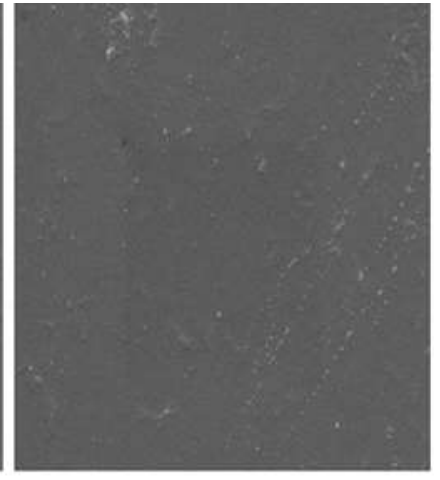

EC+ESTER strength and elongation property as well. Thus the ester of FA and COFA could compete with any type of conventional plasticizer.

Figure 4.SEM images of ethyl cellulose (EC) film surfaces. Control=EC, Experimental $=\mathrm{EC}+\mathrm{ESTER}$

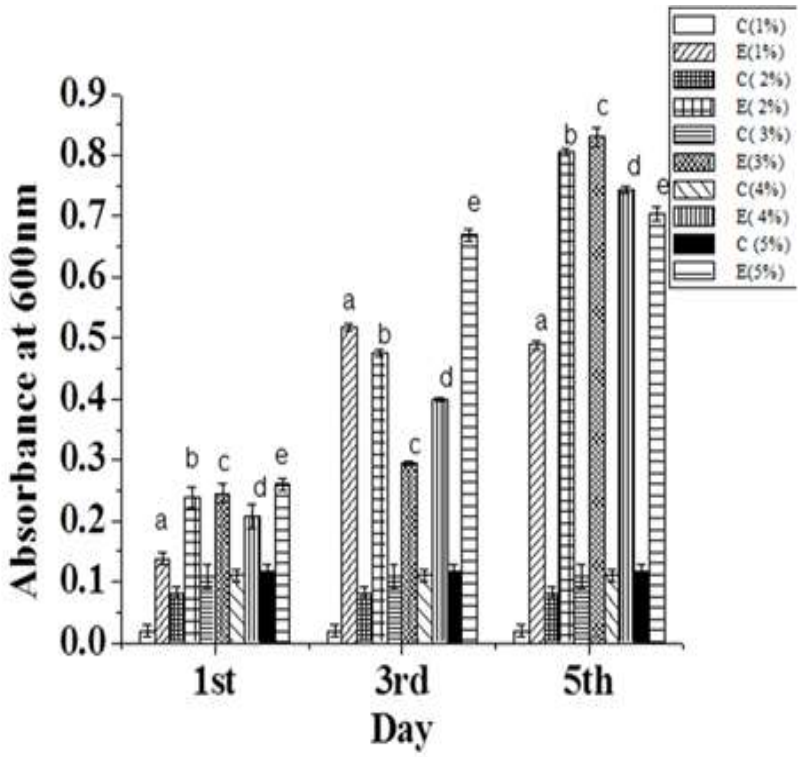

Figure 2. Spectrophotometric study (Absorbance at $600 \mathrm{~nm}$ ) for the growth of microorganism (Ochrobactrum pseudintermedium) in the $\mathrm{BH}$ media where FA-COFA ester was added at different concentrations ranging from $1 \%$ to $5 \%(\mathrm{w} / \mathrm{v})$ and the study was continued for five days. Where C: control set and E: experimental for each concentration of FA-COFA. Values are Mean \pm SEM. $\mathrm{P}<0.05, \mathrm{n}=3$

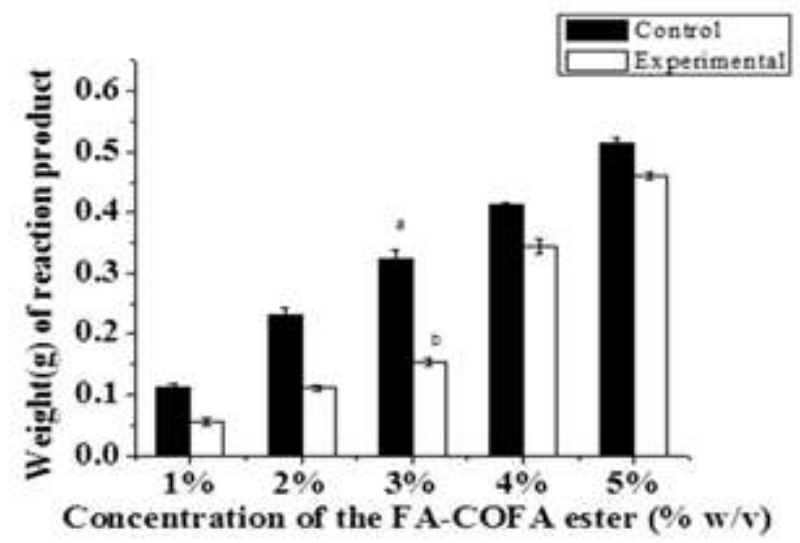

Figure 3. Gravimetric study of the FA-COFA ester at different concentrations $(1 \%, 2 \%, 3 \%, 4 \%$ and $5 \% \mathrm{w} / \mathrm{v})$ after the five days study of microbial biodegradation. Control= Weight $(\mathrm{g})$ of the ester in the media without bacterial inoculum. Experimental= loss of weight ( $\mathrm{g}$ ) of the ester in the media containg bacterial inoculum.

Values are represented as Mean \pm SEM.

aSignificant at $<0.05$ in FA-COFA ester at $3 \%(\mathrm{w} / \mathrm{v})$ concentration with the experimental group.

${ }^{\mathrm{b}}$ Significant at 0.05 in FA-COFA ester at $3 \%(\mathrm{w} / \mathrm{v})$ concentration.with the control group

\section{Conclusion}

The present study described the successful production of FACOFA ester by lipase catalyzed esterification reaction between FA and COFA. The yield of ester was very satisfactory when the reaction was carried out at $60^{\circ} \mathrm{C}$ temperature with $3: 1$ molar ratio of FA and COFA and 10\% (w/w) lipase concentration for $5 \mathrm{~h}$. The time required to obtain the desirable yield was also very satisfactory. The ester was biodegradable in nature to a certain entent of exposure to the environment. Future studies on the 
performance parameters will establish the suitability of this ester as plasticizer for different kinds of resin.Addition of this bio sourced product such as FA-COFA ester as a novel plasticizer exhibited a better performance than the ethyl cellulose films without the plasticizer. In future the ester will definitely be the substitute of any conventional plasticizer. Therefore, it can be said that ethyl cellulose film containing ester of FA and COFA is a completely bio based product, which can be a substitute to the conventional plasticized films in various industries.

\section{References}

1. Z.Xiong, L. Zhang, S. Ma, Y. Yang, C.Zhang, Z. Tang and J. Zhu, "Effect of castor oil enrichment layer produced by reaction on the properties of PLA/HDI-g-starch blends," Carb. Polym,vol.94, pp.235-243, April 2013.

2. O. Köse, M Tüter., A.H.Aksoy, "Immobilized Candida antarctica lipase-catalyzed alcoholysis of cotton seed oil in a solvent-free medium," Bioresour.Technol,vol.83,pp.125129,June 2002

3. F.T Sejidov, Y.Mansoori, N. Goodarzi, "Esterification reaction using solid heterogeneous acid catalysts under solvent-less condition,” J. Mol.Catal A: Chem,vol.240,pp.186-290,October 2005.

4. Y.Shimada., Y. Watanabe, A.Sugihara and Y. Tominaga , "Enzymatic alcoholysis for biodiesel fuel production and application of the reaction to oil processing," J. Mol.Catal b: Enz, vol. 17,pp.133-142,June 2002.

5. A. Sengupta., T. Dey, M. Ghosh, J.Ghosh and S Ghosh, "Enzymatic synthesis of furfuryl 'alcohol ester with oleic acid by Candida antarctica Lipase B and its Kinetic Study," J. Inst. Eng (India): Series E,vol.93,pp.31-36,August 2012.

6. M.Ghosh.and D.K. Bhattacharyya, " Enzymatic Preparation of Polyethylene Glycol Esters of Castor Oil Fatty Acids and Their Surface-Active Properties," J .Surf. and Deterg,vol.1,pp.503505, October 1998.

7. D. Firestone, R.C. Walker, "Official Methods and Recommended Practices of the American Oil Chemists' Society”, R.C. Walker, D. Firestone ,Eds. Illinois : American Oil Chemists' Society,1987, pp. Cd-3a.

8. M.Kates. "Techniques for separation of lipid mixtures." T.S. Work, E. Work,Eds. "Laboratory Techniques in Biochemistry and molecular Biology," Amsterdam: North Holland Publishing Company,1972,pp 442.

9. L.D. Metcalfe, A.A.Schmitz, J.R. Polka, "Rapid preparation of fatty acid esters from lipids for gas chromatographic analysis," Anal. Chem,vol. 38,pp.514-515,March 1966.

10. O.Saravari, S. Praditvatanakit, "Preparation and properties of urethane alkyd based on a castor oil/jatropha oil mixture,’Prog.Org.Coat,vol.76,pp.698-704,April 2013.

11. C. Teyssier, H Marchandin., H Jean-pierre., A.Masnou, G. Dusart and E. Jumas-Bilak, "Ochrobactrum pseudintermedium sp. nov., a novel member of the family Brucellaceae, isolated from human clinical samples," Int. J. Syst. Evol. Microbiol,vol. 57,pp. 1007-1013, 2007.

12. R.Bhatt., D.Shah., K.C. Patel and U. Trivedi, "PHA-rubber blends:Synthesis ,characterization and biodegradation," Bioresour.Technol,vol.99,pp.4615-4620,July 2008.

13. D. Yang, X. Peng, L .Zhong, X.Cao, W.Chen, , X.Zhang, , S.Liu, R.Sun, "Green" films from renewable resources: Properties of epoxidized soybean oil plasticized ethyl cellulose films."'Carb. Polym ,vol.103,pp.198-206, December 2014.
About Author (s):
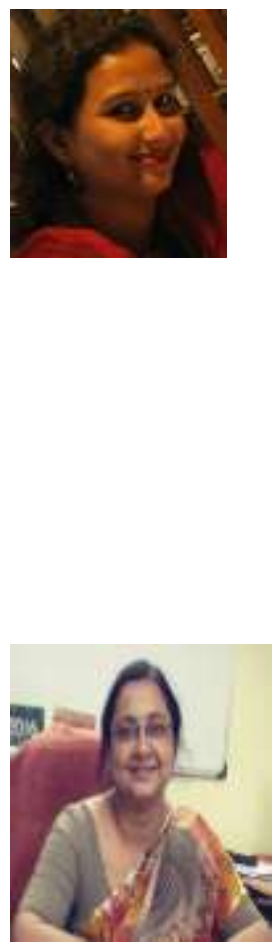

Dr. Mahua Ghosh studied Chemistry and Chemical Technology (Oil Technology) at the University of Calcutta. She also received her Ph.D (tech) degree from University of Calcutta.

Besides more than 11 years of teaching experience she has 13 years research experience. She is a member of American Oil Chemists' Society, Oil Technologists' Association of India, Indian Chemical Society, Indian Institute of Chemical Engineers, Association of Food Technologists of India and Electron Microscope Society of India. Her research focuses edible and non-edible applications of fats and oils. She is the head of an NABL accredited laboratory for oil analysis. 